\title{
Perbedaan antara Metode Pembelajaran Satu Arah dan Role-Play pada Program ETLS (Emergency Trauma Life Support) dan CSR (Clinical Skill Refreshment) terhadap Nilai Obstetri Ginekologi pada Mahasiswa FK UMM
}

\author{
Kusuma Andriana* \\ "Fakultas Kedokeran Universitas Muhammadiyah Malang \\ Jl. Rambutan 2 Malang - 65116, Hp. 081555666621 \\ email : andrianakusuma@yahoo.com
}

\begin{abstract}
Clinical skills are one of the 7 competency areas at the Indonesian Doctors Competency Standards (SKDI). The learning model can be varied, one of which is role play. FKUMM has changed the method of learning clinical skills from one way to the role-play method in the ETLS (Emergency Trauma Life Support) and CSR (Clinical Skill Refreshment) program, but its impact evaluation has never been done. To determine the difference between one-way learning methods and role-play in ETLS and CSR programs on the scores of gynecological obstetrics in FK UMM students. Analytic observational study with cross sectional method on grades of ETLS - CSR at groups 14 and 15 (one-way method) and group 20 stages 1 and 2 (role-play method) and grades of on obstetric and gynecology clinics from students who had following ETLS-CSR waves 14, 15 and 20 stages 1 and 20 stages 2. The average, maximal and minimum scores of medical student at ETLS-CSR and gynecology obstetric department with role-play were higher than the one-way method. To see the differences in one-way and role-play methods, Mann Whitney tests were performed on obstetrics and gynecology stations at OSCE ETLS and CSR with $\alpha=0,000(<0,005)$, carried out by independent sample T test on student's scores at obstetric and gynecological department with $\alpha=0,000(<0,005)$ and the Wilcoxon Signed Ranks test was conducted to see the effect of the ETLS-CSR learning pattern on the student's score at gynecological obstetric department with $\alpha=0,000(<0.005)$. There were significant differences between the one-way learning and role-play method in the ETLS and CSR program on the scores of medical student at gynecological obstetrics of University of Muhammadiyah Malang
\end{abstract}

Kata Kunci : one-way learning method, role-play, clinical skills

\section{Abstrak}

Keterampilan klinis merupakan satu dari 7 area kompetensi pada Standar Kompetensi Dokter Indonesia (SKDI). Model pembelajarannya bisa beragam salah satunya adalah bermain peran (role-play). FK UMM sudah melakukan perubahan metode pembelajaran keterampilan klinik dari satu arah ke metode role-play di program ETLS (Emergency Trauma Life Support) dan CSR (Clinical Skill Refreshment), namun belum pernah dilakukan evaluasi dampaknya. Untuk mengetahui perbedaan antara metode pembelajaran satu arah dan role-play di program ETLS dan CSR terhadap nilai obstetri ginekologi pada mahasiswa FKUMM. Penelitian observasional analitik dengan cara iris silang (cross sectional) terhadap nilai ETLS - CSR gelombang 14 dan 15 (metode satu arah) dan gelombang 20 tahap 1 dan 2 (metode role-play) dan nilai kepaniteraan klinik obstetrik dan ginekologi dari mahasiswa yang telah mengikuti ETLS-CSR gelombang 14, 15 dan 20 tahap 1 serta 20 tahap 2. Diperoleh nilai rerata, maksimal dan minimal OSCE ETLS-CSR dan kepaniteraan klinik obstetri ginekologi metode role-play lebih tinggi daripada metode satu arah. Untuk melihat perbedaan metode satu arah dan role-play dilakukan uji Mann Whitney pada nilai ETLS dan CSR station obstetri dan ginekologi dengan $\alpha=0,000(<0,005)$, dilakukan independent sample T test pada nilai kepaniteraan obstetri dan ginekologi dan didapatkan nilai $\alpha=0,000(<0,005)$ dan dilakukan uji Wilcoxon Signed Ranks untuk melihat pengaruh pola pembelajaran ETLS-CSR terhadap nilai kepaniteraan klinik obstetri ginekologi dan diperoleh nilai $\alpha=0,000(<0,005)$. Terdapat perbedaan bermakna antara metode pembelajaran satu arah dan role-play di program ETLS (Emergency Trauma Life Support) dan CSR (Clinical Skill Refreshment) terhadap nilai obstetri ginekologi pada mahasiswa FK UMM

Kata Kunci : metode satu arah, metode role-play, keterampilan klinis 


\section{PENDAHULUAN}

Kemampuan keterampilan klinis (skill) adalah hal penting dalam pembelajarn pendidikan kedokteran yang dibutuhkan dalam menangani pasien ${ }^{10}$. Keterampilan klinis merupakan satu dari 7 area kompetensi yang tertuang di SKDI dan diharapkan mahasiswa mampu melakukan prosedur klinis yang berkaitan dengan masalah kesehatan dengan menerapkan prinsip keselamatan pasien, keselamatan diri sendiri, dan keselamatan orang lain 5,4 .

Mahasiswa Fakultas Kedokteran UMM yang telah menyelesaikan pendidikan preklinik akan memasuki tahap pendidikan profesi. Persiapan yang dilakukan adalah dengan membekali mahasiswa dengan suatu program Emergency Trauma Life Support (ETLS) - Clinical Skill Refreshment (CSR). (FKUMM, 2014) Emergency Trauma Life Support (ETLS) - Clinical Skill Refreshment (CSR) yang telah berlangsung lebih dari sepuluh tahun mengalami berbagai perubahan metode pembelajaran. Perubahan metode pembelajaran yang terakhir dilakukan pada tahun 2014, yaitu pembelajaran satu arah menjadi metode role-play.

Model pembelajaran bermain peran (roleplay) adalah salah satu model strategi pembelajaran aktif yang diperankan oleh mahasiswa seperti drama, simulasi, permainan, demonstrasi kasus dan berbagai hal $^{3}$. Metode ini merupakan satu dari metode pembelajaran orang dewasa (adult learning) dan membutuhkan pembelajar yang mempunyai rasa ingin tahu, mandiri, mental sebagai pembelajar, kesiapan untuk belajar, orientasi yang jelas, dan memilki motivasi tinggi untuk belajar ${ }^{6}$.
Selama 4 tahun pelaksanaannya belum pernah dilakukan evaluasi dampak perubahannya terutama perubahan nilai mahasiswa..

\section{METODE PENELITIAN}

Penelitian ini merupakan penelitian observasional analitik dengan cara iris silang (cross sectional). Tujuannya untuk mengetahui perbedaan antara metode pembelajaran satu arah dan role-play di program ETLS dan CSR terhadap nilai obstetri ginekologi pada mahasiswa FKUMM. Sampel adalah Data nilai ETLS - CSR gelombang 14 dan 15 (metode satu arah) dan gelombang 20 tahap 1 dan 2 (metode role-play) dan data nilai kepaniteraan klinik obstetrik dan ginekologi dari mahasiswa yang telah mengikuti ETLS-CSR gelombang 14, 15 dan 20 tahap 1 serta 20 tahap 2. Analisis statistik yang dilakukan adalah independent-sample $T$ test untuk membandingkan rerrata dua kelompok sampel independen bila sebaran data normal Bila sebaran data tidak normal, akan dilakukan tranformasi data, dan bila sebaran data tetap tidak normal akan dilakukan uji non parametrik dengan uji Mann Whitney. Paired $\mathrm{T}$ test dilakukan pada sebaran data yang normal untuk membandingkan rerrata dua kelompok sampel yang saling berhubungan, Bila sebaran tidak normal akan dilakukan uji non parametrik dengan Wilcoxon Signed Ranks test.

\section{HASIL}

Dari data deskriptif tabel 4.1 dan 4.2 diperoleh rerata nilai, nilai maksimal dan nilai minimal OSCE ETLSCSR dan kepaniteraan klinik obstetri ginekologi dengan metode role-play lebih tinggi daripada metode satu arah. 
Tabel 1. Data nilai OSCE ETLS-CSR Obstetri dan ginekologi

\begin{tabular}{|c|c|c|c|c|c|}
\hline $\begin{array}{l}\text { ETLS } \\
\text {-CSR }\end{array}$ & $\mathrm{N}$ & $\begin{array}{l}\text { Rerat } \\
\text { a } \\
\text { Nilai }\end{array}$ & $\begin{array}{c}\text { Nilai } \\
\text { Maksim } \\
\text { al }\end{array}$ & $\begin{array}{l}\text { Nilai } \\
\text { Minim } \\
\text { al }\end{array}$ & $\begin{array}{c}\text { Simpang } \\
\text { an } \\
\text { Baku }\end{array}$ \\
\hline Pola & 6 & 52,74 & 78,13 & 30,00 & 10,09 \\
\hline Lama & 3 & 62,68 & 93,00 & 28,50 & 17,26 \\
\hline Pola & 7 & & & & \\
\hline Baru & 9 & & & & \\
\hline
\end{tabular}

Sumber : data primer

Tabel 2. Data nilai Kepaniteraan Klinik Obstetri dan GInekologi

\begin{tabular}{cccccc}
\hline ETLS & N & Rerat & Nilai & Nilai & Simpang \\
-CSR & & $\begin{array}{c}\text { a } \\
\text { Maksim } \\
\text { Minim } \\
\text { an }\end{array}$ & $\begin{array}{c}\text { al } \\
\text { Baku }\end{array}$ \\
\hline Pola & 6 & 68,03 & 78,13 & 58,11 & 3,81 \\
Lama & 3 & 75,25 & 85,59 & 65,91 & 3,6 \\
Pola & 7 & & & & \\
Baru & 9 & & & & \\
\hline
\end{tabular}

Sumber : data primer

Untuk melihat perbedaan metode satu arah dan roleplay dilakukan uji Mann Whitney pada nilai ETLS dan CSR station obstetri dan ginekologi, diperoleh nilai $\alpha=0,000(<0,005)$, kemudian dilakukan independent sample $T$ test pada nilai kepaniteraan obstetri dan ginekologi dan didapatkan nilai $\alpha=$ 0,000 $(<0,005)$ dan dilakukan uji Wilcoxon Signed Ranks untuk melihat pengaruh pola pembelajaran ETLS-CSR terhadap nilai kepaniteraan klinik obstetri ginekologi dan diperoleh nilai $\alpha=0,000(<0,005)$.

Untuk mengetahui apakah terdapat pengaruh pola pembelajaran di ETLS-CSR terhadap nilai kepaniteraan klinik obstetri ginekologi dilakukan uji nonpramaterik dg Wilcoxon Signed Ranks test.
Terdapat 22 sampel yang mengalami penurunan nilai (negative ranks) dengan selisih rerata penurunannya 42,81, sementara terdapat 120 sampel yang mengalami peningkakatan nilai (positive ranks) dengan selisih rerata peningkatannya adalah 80,15. Hasil uji statistik diperoleh $\alpha: 0,000(<0,05)$, sehingga disimpulkan terdapat perbedaan yang bermakna antara nilai kepaniteraan klinik obstetri ginekologi pada mahasiswa dengan metode ETLSCSR metode sartu arah dan metode role-play

\section{DISKUSI DAN PEMBAHASAN}

Setiap dokter diharapkan kompeten melakukan pemeriksaan klinis. Diberlakukannya SKDI merupakan upaya untuk menstandarkan kompetensi lulusan dokter Indonesia dari sisi keilmuan, keterampilan klinis dan sebagainya ${ }^{5}$.

Fakultas Kedokteran UMM mengupayakan pembekalan mahasiswa yang akan melanjutkan pendidikan profesi dengan menjalani program ETLSCSR. Dirasa perlu melakukan perubahan metode pembelajaran keterampilan klinik (skill), sehingga metode satu arah yang dilakukan kemudian berganti menjadi metode role-play.

Hasil dari penelitian ini menunjukkan perbedaan rerata nilai yang bermakna antara pola lama (metode satu arah) dan pola baru (metode roleplay ) Di program ETLS-CSR maupun nilai kepaniteraan klinik obstetri dan ginekologi. Hal ini sejalan dengan Acharya,et al (2014) $)^{1}$ yang menyebutkan bahwa role-play merupakan metode yang efektif untuk pembelajaran di FK. Acharya,et al $(2014)^{1}$ melakukan penelitian terhadap 24 mahasiswa FK tingkat akhir yang dibagi menjadi 3 kelompok yaitu kelompok sistem kardiovaskular, sistem 
respirasi dan sistem abdomen yang melakukan serial role-play. Selama 2 bulan dilakukan pemberian presensitisasi berupa kasus-kasus singkat yang di ranah kognitif, afektif dan psikomotor setelah itu kemudian dilanjutkan post sensitisasi dengan skenario yang akan diperankan. Didapatkan perubahan yang bermakna pada kognitif, afektif dan psikomotor sampel.

Penelitian ini juga sejalan dengan Nestel \& Tierney, (2007) ${ }^{7}$ yang menyatakan bahwa role-play merupakan metode yang sangat membantu untuk skill komunikasi walaupun sampel belum pernah memiliki pengalaman untuk melakukan sebelumnya. Dalam penelitiannya, Nestel \& Tierney $(2007)^{7}$ mengambil 284 sampel mahasiswa tahun pertama untuk mengikuti program skill komunikasi. Sebelum dan sesuah penelitian, sampel diminta untuk mengisi kuesioner, dan diperoleh 22,2 \% yang menjawab bahwa role-play tidak membantu pembelajaran,sementara 96,5 \% lainnya merasa terbantu. Kunci yang berperan dalam keberhasilan role-play adalah adanya panduan yang memadai, kejelasan peran dan tugas selama kegiatan, adanya umpan balik dan interaksi antara fasilitator dan mahasiswa., dan adanya evaluasi terhadap simulasi yang sudah dijalankan.

Berbeda dengan Stevenson, et al $(2002)^{8}$ yang melakukan penelitian role-play menggunakan kwesioner pada 195 mahasiswa FK, 128 mahasiswa bidang bisnis dan 72 mahasiswa psikologi. Semuanya adalah mahasiswa yang baru menjalani pendidikannya di minggu pertama di universitas. Diperoleh hasil bahwa metode ini $75 \%$ tidak efektif karena di tahun pertama, mahasiswa FK masih belum siap dengan sistem student centered learning, sementara $54 \%$ mahasiswa bisnis dan $22 \%$ mahasiswa psikologi mengatakan pembelajaran ini tidak bermanfaat.

Vogel D \& Sigrid H $(2016)^{10}$ melakukan revieuw terhadap 43 hasil penelitian teknik pembelajaran skill dengan role-play. Hasil OSCE menunjukkan nilai lebih baik pada metode role-play, mahasiswa yang menggunakan multimedia untuk pembelajarannya, mahasiswa yang mendapat simulasi sebelumnya, mahasiswa yang diberikan feed back Sementara tidak diperoleh perbedaan nilai pada mahasiswa dengan fasilitator yang dokter umum atau spesialis. Kelompok roel play optimal adalah 1 fasilitator mendapingi 4 mahasiswa. Kelemahan penelitian karena hanya memilih 2 periode pola lama dan 1 periode baru, yang belum dapat menggambarkan secara detail hasil pembelaharan metode role-play.

\section{KESIMPULAN}

Terdapat perbedaan yang bermakna antara metode pembelajaran satu arah dan role-play pada program ETLS dan CSR terhadap nilai obstetri ginekologi pada mahasiswa FK UMM.

\section{DAFTAR PUSTAKA}

1. Acharya, S., Shukla, S., Acharya, N., \& Vagha, J. 2014. Role play - an eff ective tool to teach clinical medicine, 2(2). http://doi.org/10.5455/jcme.20140619111139

2. Erturk, E. 2015a. Evaluation of Role Play as a Teaching Strategy in a Systems Analysis and Design Course. International Journal of Learning, 13x(November), 150-159. Retrieved from

https://www.researchgate.net/publication/284285 
165

3. Erturk, E. 2015b. Role Play as a Teaching Strategy,

(October). http://doi.org/10.13140/RG.2.1.4287.9449

4. Fitri, A. D. 2015. Penerapan problem based learning ( PBL ) dalam kurikulum berbasis kompetensi. JMU, 4(1), 95-100.

5. Konsil Kedokteran Indonesia. 2012. STANDAR KOMPETENSI DOKTER INDONESIA.

6. Konwles, M. S., Holton, E. F., \& Swanson, R. A. 2005. The ADULT LEARNER 6th ed.. AMsterdam: Elsevier Ltd.

7. Nestel, D., \& Tierney, T. 2007. Role-play for medical students learning about communication : Guidelines for maximising benefits, 9, 1-9. http://doi.org/10.1186/1472-6920-7-3

8. Stevenson, K., Sander, P., Stevenson, K., \& Sander, P. 2002. Medical students are from Mars business and psychology students are from Venus University teachers are from Pluto ?, 24(1), 2731. http://doi.org/10.1080/00034980120103441

9. Suen, W., Hughes, J., \& Russell, M. 2011. From Role-playing To Real-playing: Teaching Effective Facilitation Skills, (June), 1-27.

10. Vogel Daniela; Sigrid Heredza. 2016. Basic practical skills teaching and learning in undergraduate medical education - a review on methodological evidence. GMS Journal for Medical Education, 33(4), 1-19.

11.Zulharman. 2011. Perancangan Objective Structured Clinical Examination (OSCE ) untuk Menilai Kompetensi Klinik. JIK, 5(1), 7-12. 